\title{
3. Definition of Anatomical Features
}

Xylem anatomy is described on the basis of the variable in Diospyros with markedly heterogeIAWA List of Microscopic Features for Hardwood neous rays (IAWA, 1989). Ray height is not exIdentification (Wheeler et al. 1989). However, ceeding $1 \mathrm{~mm}$ in both Dalbergia and Diospyros. three relevant anatomical features for Dalber- Four classes are determined for the total ray gia and Diospyros species identification have height in tangential section, along the ray axis. been added to the IAWA list. For those addition- Size measurements of all wood elements are al features, we used the code in the form "X.\#" presented as minimum, mean and maximum where $X$ is the modified relative IAWA character (e.g. 10-24-50 $\mu \mathrm{m}$ ). number and "\#" is a consecutive number.

9.1 - Vessels solitary and in short radial multiples of 2 to 3 elements simultaneously present

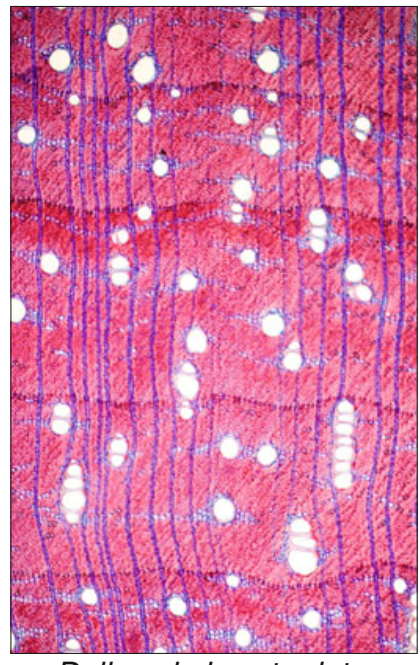

Dalbergia bracteolata

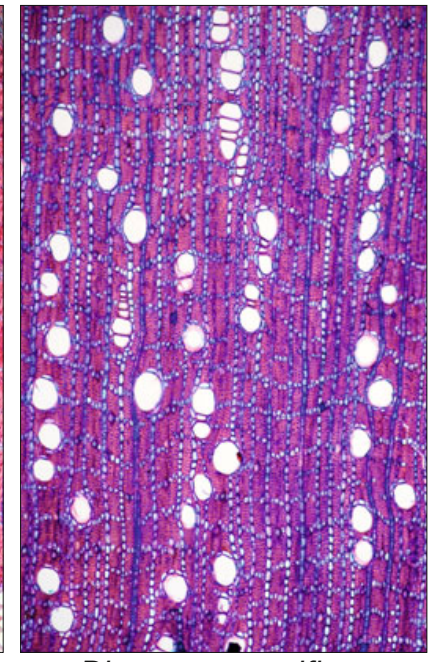

Diospyros acutiflora

96.1 - Rays uni-and biseriate simultaneously present

Ray width is determined on tangential sections by counting the number of cells in the widest part of the rays, perpendicular to the ray axis. Rays uni- and biseriate are often simultaneously presents in both Dalbergia and Diospyros, in this case width predominance is always determined.

102.1 - Ray height $<100 \mu \mathrm{m}$

102.2 - Ray height 100-200 $\mu \mathrm{m}$

102.3 - Ray height 200-500 $\mu \mathrm{m}$

102.4 - Ray height $>500 \mu \mathrm{m}$

Detailed ray height data are given in descriptions because this feature may be helpful in distinguishing between species. Ray height is quite 